\title{
ACTINOMICOSE CERVICAL EM EQUINO PURO SANGUE INGLES.
}

\author{
Eduardo do Nascimento MOS* \\ Romeu MACRUZ* \\ O. LENCI*
}

RFMV-A/13

MOS, E.N.; MACRUZ, R.; LENCI, O. Actinamico renvical em equino Puro Sangue Ingles. Rev. Fac. Med. vet. Zootec. Univ. S. Paulo, 15 (1):097-100, 1978

RESUMO: Foi apresentado o caso de actinomicose em equino P.S.I. de tres anos de idade, femea que apresentava formaçäo tumoral no ganglio submaxilar. Inicialmente o processo foi confundido clínicamente com adenite equina. Feita a estirpaçdo cirirgica houve recidive do processo que atingiu apos 6 (seis) meses tamanho aproximadamente de $10 \mathrm{~cm}$ de didmetro. O diagnótico se estabeleceu pela biópsia da lesão, exame histopatológico seguido do cultivo do material, confirmando quadro de actinomicose.

UNITERMOS: Actinomicose; equinos*; Bibpsia*

\section{INTRODUÇÃO}

As actinomicose é doença granulamatosa crônica do homem e animais. Ocorre em grande número de espécies, principalmente em bovinos, sob a forma cérvico facial, simulando frequentemente processos tumorais. Em cavalos, a localização cervical é fato evidente, sendo que na maioria das vezes ela ocorre em associação com infecçбes por Brucella abortus ${ }^{2}$.

Para outros a doença em equinos é quase que exclusiva do cord̄o testicular, instalando-se consecutivamente a castraçāo ${ }^{5}$, portanto de natureza exógena. Em nosso meio, a localização cervical em equinos parece se constituir em fato de ccorrência rara, não havendo na literatura nacional trabalho sobre o assunto. Correa Filho $^{3}$
(1966) em estudo comparativo da ocorrência de moléstias em 14.893 atendimentos de equinos, não verificou um único caso de actinomicose.

\section{DESCRIÇĀO DO CASE}

Equino puro sangue inglés, sexo feminino, três anos de idade, apresentando formação tumoral ao nível do gânglio submaxilar. Inicialmente o caso foi confundido com "adenite equina". Posteriormente julgando tratar-se de tumor foi indicada cirurgia. Houve recidiva do processo, com aumento da formação tumoral que atingiu em 6 meses após o ato cirúrgico, aproximadamente $10 \mathrm{~cm}$ de diâmetro. Recorreu-se então a biópsia e por exame histopato.

* Veterinário.

Jockey Club de São Paulo.

* Professor Assistente Doutor.

Institu to de Ciências Biomédicas da USP. 
Iógıco estabeleceu-se diagnóstico de "actinomicetoma" tendo-se verificado nos cortes de gânglio linfático, corados pelo H.E. e P.A.S. parenquima com inúmeras formaçð̄es actinomicóticas de dimensōes variadas, geralmente arredondadas e bordos com filamentos radiados. Ao redor, acentuado exsudato purulento por polimorfos nucleares neutro-filos e mais externamente regular quantidade de plasmacelulas, alguns linfócitos e poucos eosinófilos. Chamou atenção a ausência de células gigantes e macrófagos que ocorrem normalmente em granulomas do tipo. Após foi feita cultura e isolamento e para tanto recorreu-se a técnica recomendada por Lacaz' Bailey e $\operatorname{Scot}^{1}$, na qual o material purulento foi lavado em salina e centrifugado várias vezes $\mathrm{e}$ inoculado em vários tubos (de 4 a 6) de meio de Tioglicolato e de $\mathrm{BHI}$, cuidando-se de nāo produzir bôlhas de ar ao tempo em que esmagou-se os grãos parasitários contra as paredes do tubo com meio de cultura. Os meios foram incubados a $37^{\circ} \mathrm{C}$ sendo que os tubos com Fioglicolato foram diretamente em estufa e os de BHI préviamente em atmosfera de $\mathrm{CO}_{2}$ a 10\% Após 5 dias de incubação notou-se colonias típicamente pequenas, discretas tipo "migalha de pão"6 que aspiradas, esmagadas, fixadas e coradas ao Gram revelaram massas entrelaçadas de filamentos que se ramificam e formas fragmentadas "tipo differoide".

À análise bioquímica do microrganismo analisando-se através substratos como se segue, obteve-se os seguintes resultados:

\begin{tabular}{|c|c|c|c|}
\hline \multicolumn{2}{|c|}{ Catalase -} & \multicolumn{2}{|c|}{ Redução de Nitratos + } \\
\hline \multicolumn{2}{|c|}{ Amido +} & \multicolumn{2}{|l|}{ Indol $\mapsto$} \\
\hline \multicolumn{2}{|c|}{ Gelatinase - } & Rafinose & Ac. \\
\hline \multicolumn{2}{|c|}{ Leite Tornassolado Acidif. s/coag. } & Amido & Lig. \\
\hline Glicose & Ac. & Glicogênio & - \\
\hline Xilose & Ac. & \multicolumn{2}{|c|}{ Crescimento em Anaerobiose } \\
\hline Manitol & Ac. & \multicolumn{2}{|c|}{ e em Microaerofilia +} \\
\hline
\end{tabular}

\section{DISCUSSÃO E CONCLUSÃO}

O diagnóstico histopatológico da actinomicose dos tecidos moles pode levar a confusð̄es com a actinobacilose, principalmente pelo fato de serem histológicamente muito semelhantes, somado o fato da actinobacilose, ocorrer particularmente em glândulas linfáticas ${ }^{8}$. 0 diagnóstico definitivo somente pode ser feito após isolamento do agente. $\mathrm{O}$ isolamento de actinomicetos anaeróbios ou microaerofilos de cavidades naturais principalmente da bôca e cavidades do homem e animais ${ }^{7}$ permıtem admitir-se que a infecçāo apareça espontâneamente sem que haja necessidade de que o agente seja veiculado através fragmentos vegetais. Baseados no isolamento do presente caso, tudo leva a crer que seja o Actinomyces israelii o agente do processo, não se constituindo em caso extremamente raro em animais, uma vez que o mesmo anteriormente foi assinalado em $\operatorname{coelhos}^{9}$ e em bovinos também ${ }^{4}$. Não temos informações no presente caso de qualquer ferimento aue possa ter ocorrido anteriormente no animal e que tenha servido como base para instalação da infecção. 
MOS, E.N.; MACRUZ, R.; LENCI. O. Cenvical actinomycosis in thoroughbred. Rev. Fac. Med. vet. Zootec. Univ. S. Paulo, 15 (1):097.100, 197ð

SUMMARY: It was presented a case of actinomycosis in a three years old female equine presenting a tumoral formation in the submaxilary lymphatic glands. At the first, the process was confused with equine adenitis. After surgical remotion of the tumor a relapse ocurred and after 6 months it reached approximatily $10 \mathrm{~cm}$ sixe. Diagnosis was established after biopsy of lesion, histo pathological examination followed by cultivation of the material, confirming a case of actinomycosis.

UNITERMS: Actinomycosis, equines*; Biopsy*.

\section{REFERĒNCIAS BIBLIOGRÁFICAS}

1 - BAILEY, A.W. \& SCOTT, G.E. Diagnóstico microbiologico. B. Aires, Ed. Médica Panamericana, 1973.

2 - BUXTON, A. \& FRASER, G. Animal micro. biology. New York, Blackwell Scientific Publ., 1977. v.1.

3 - CORREIA, F.E.A. Incidência das doenças nos cavalos militares. Rev. Med. Vet., 1 (3): 195-206, 1966.

4 EMMONS, C.W.; BINFORD, H.C.; UTZ, J.P. Medical mycology. 2.ed. New York, Lea \& Febiger.

5. FEREIRA, A.J. Doenças infecto contagiosas dos animais domésticos. 2.ed. Lisboa, Fund ação Calouste Gulbenkian, s.d.
6 - KEUSCH, G.T. \& WEINSTEIN, L. Doenças $e$ bactérias anaeróbias. Kalamazoo, The Upjohn Company, 1975.

7 - LACAZ, C.S. Micologia médica. 5.ed. São Paulo, Sarvier \& Mec, 1973.

8 - PLUMMER, P.J.G. Actinomycosis. Canad. J. Comp. Med., 10 (12): 331-7, 1946.

9 - SOERENSEN, B. \& SALIBA, A.M. Actino. micose espontônea em coelhos. O Biológico, 27 (6): 131-4, 1961.

Aprovado para publicação em 04.09.1978 